\title{
The Advantages of BIM Application in EPC Mode
}

\author{
Hongbo Qin ${ }^{*}$ \\ School of Management Engineering, Zhengzhou University, Henan Vocational College of Judicial Police Officers, \\ Zhengzhou 450001, China \\ "Corresponding author: 121425031@qq.com
}

\begin{abstract}
Applying BIM in the model of EPC General contracting, general contractor, designer, constructor, Supervisor and other professional sub contractors can share resource which can achieve the project information, standardization, visualization, collaborative and ultimately make the project quality, schedule, cost, safety and other objectives to achieve maximum.
\end{abstract}

Key words. EPC model BIM apply Advantages

\section{The mode and characteristics of epc general contract}

\subsection{EPCMode}

Design, procurement and construction (EPC) / Turnkey: design, procurement and construction contract refers to the general contractor enterprises in accordance with the contract, to undertake the project design, procurement, construction, commissioning and service work, quality, safety, schedule and cost of the Contractor shall be responsible for the overall project. Turnkey general contracting is an extension of the general contracting business and the responsibility of the design procurement construction. It is a project that meets the use function and the conditions of use.

Design build (D-B): Design - construction contract refers to the general contractor enterprises in accordance with the contract, to undertake the project design and construction, and the quality, safety, schedule and cost of the Contractor shall be responsible for the overall project. According to the different size and type of the project and the owner's requirement, the general contracting of the project can also adopt the design, procurement and construction (E-P), procurement and construction contracting (P-C, etc.).

\subsection{The characteristics of EPC}

1.2.1 To give full play to the role of the market mechanism. Not only the owner of the project as an investment project first, but also the architect, the contractor, the construction division are from this priority. In order to participate in the competition effectively, the whole project is divided into several relatively independent work packages. Responsible for the design, manufacture or supply of materials and components for each work package, and responsible for the construction and installation of all the work packages. This dual coordination feedback, relying on the project related parties are able to follow the common recognition of the control procedures, national norms and technical standards.

1.2.2 Consulting engineers to provide a complete design of the professional, but the design stage only to the initial design or expand the depth of the preliminary design, the detailed design of the construction plans, and the latter is completed by the contractor. In particular, some of the more independent sub sub project construction plans, and 
sometimes also known as the two design, by the professional subcontractor to complete, but need to be approved by the architect.

1.2.3 architect known as the market situation, they will not only design as its architectural works, and implement the cost control in the whole design process, must have overall awareness of cost control, cost control is particularly important in this stage. Set up design is the key to influence the success or failure of the owner's investment.

\section{The application of bim technology}

BIM is a kind of technology, that is, how to use information technology to carry out the construction of technical activities. At the same time BIM is a kind of thinking, how to analyze the whole process of thinking, how to use the analysis of the problem and solve the problem of thinking.

BIM is the abbreviation of building information model. Building information model integrated geometric model information, functional requirements and performance of all components, the use of all the information the whole life cycle of a building model covers separate buildings within the project, including the process of information, such as the construction schedule, construction process, maintenance management and property management etc..

BIM technology is a platform (integrated professional information model, field model, mechanical model and temporary model, schedule, budget, drawings and other business data; (three) the direction of technology, production, business), five core (integrated model, construction simulation, schedule control, cost control, quality tracking and management, ten application: basic application; pipeline management, construction simulation, schedule control, volume and price inquiry, material extraction, animation disclosure, quality tracking, drawings management, collision detection. As an important tool of information management, work efficiency can be greatly improved.

\section{The advantages of general contracting using bim under the epc mode}

Design, procurement, construction and integration in EPC mode and facilitate the application of BIM, it can realize the design, procurement and construction of collaborative work, shorten the construction period, improve management efficiency, to achieve integration, construction project information management.

\subsection{The Advantages Of the design side}

The designer can make large scale, time, complex design content and work easier, using various features of the BIM model can be analyzed and simulated and optimized performance of various design schemes of each stage (such as sunshine, wind, thermal environment, landscape visibility, noise, energy consumption, emergency treatment cost, etc.), the best performance determination of building design standards, the overall project is fundamentally improved. The designer has built a warm water and related information by using BIM software to program 360 all-round display; issued construction plans; according to the characteristics of EPC project issued by the engineering quantity statistics and engineering cost, provide visual and standardized data.

BIM design means compared with the traditional means of design, multi person collaborative design is also one of the highlights. The advantages are as follows: 1, improve the design efficiency, communication and non professionals, practical design results directly; 2 , improve the drawing quality and efficiency, quickly and accurately find the drawings of German "riddled bruise"; 3, simulate the construction, optimization of the procedure; 4, convenient construction phase of the exchange and communication; 5 , facilitate the operation and maintenance phase of the work; 6 , To integrate design and cost control.

\subsection{The Advantages of construction side}

In the construction design support can radically reduce the construction cost, shorten the construction period, improve the quality, and the stages of design and construction of the complete building information can be reserved for all owners in 
the construction operation and maintenance and lay a solid foundation, fundamentally changed the traditional management information lost caused by serious situation information. BIM construction schedule simulation and other functions can enhance the owner's control of the entire project. After the completion of the building, with the complete information of the BIM can provide for the owners of the operation, maintenance and management. Construction is a highly dynamic and complex process, the current construction project management is often used to represent the progress of the network plan, due to professional, low degree of visualization, can not clearly describe the progress of construction and a variety of complex relationships, it is difficult to image expression Dynamic Change Process of Engineering Construction. The integration of spatial information, time and cost information into a visual 5D (3D + Time + Cost) model can be intuitively and accurately reflected throughout the construction process and virtual Image progress. 5D construction simulation technology can be in the construction process of the project to develop a reasonable planning, accurate grasp of the progress of construction, and optimize the use of construction resources and scientific site layout, the entire project construction schedule, resources and quality of unified management and control to shorten the construction period, Reduce costs, improve quality. In addition, with the help of 5D model, construction companies in the project bidding will be competitive advantage, BIM can let the owners intuitive understanding of the bidding unit of the tender construction of the main control methods, construction arrangements are balanced, the overall plan is reasonable, Units of construction experience and strength to make effective assessment.

\subsection{Design and Construction Methods in EPC Mode}

In the EPC general contracting mode, the design side and construction side as a union, the design side through the BIM application fundamentally improve the performance of the building and less change, improve production management efficiency, it can reduce construction costs to improve the construction Stage of the profit rate, from the construction phase to obtain the income outside the design fee; the construction side can be in the design side with the support from the fundamental lower construction costs, the construction stage of the profit margin. In other words, in the EPC mode design and construction as a whole can achieve mutual benefit and win-win benefits can promote the application of BIM to provide a powerful driving force. This model is also suitable for China's current construction project development of the overall requirements.

\subsection{Calculation of Engineering Quantity with BIM Technology}

BIM design methods in the amount of statistical engineering compared to the original CAD drawings of equipment and materials have a greater statistical advantage. After the drawing is finished, the engineering quantity statistics can be carried out by the function of the software itself, and the relevant price information can be obtained, so that the engineering cost can be obtained, and the working efficiency of the cost budget can be greatly improved compared with the CAD design. But in this regard is not perfect function, such as electrical professional cable length of the statistics, there is no way to select the line, and the actual amount of a gap. Need to wait for further improvement of the software to solve these problems. It can also provide more accurate and intuitive data and views for final accounts.

\subsection{The advantages of the purchaser}

Using BIM technology, the integration of design, procurement, and construction is beneficial to the purchaser in the management of the project, to coordinate with the design and construction, to unify and standardize the model, to construct the physical characteristics and functions of the project Which is based on building information and provides decision-making for each stage of the construction project. The purchaser can know the material type and quantity more accurately through the model and better understand the structure of the material in the collision test.

In the EPC general contracting mode, BIM technology is used to integrate various professional contents into the BIM model. The total package, design, construction, supervision and professional subcontractors share resources and 
communicate with each other in a timely manner. A very good social benefits. EPC mode BIM application of a useful exploration, will be able to optimize the allocation of labor, material equipment approach, cost control, program management, improve the efficiency of management, but also speed up the construction of the project speed, So that the various BIM participants in different environments can benefit, has great economic value and potential, but also for the green, environmental protection, low-carbon construction provides a reliable data information support.

\section{Acknowledgments}

EPC project general contracting is to achieve "project function" as the ultimate goal which includes planning, design, procurement, construction, completion and acceptance, trial operation, operation and other stages of the implementation of a number of stages or the whole process 。 And BIM technology can play the role of information, visualization, standardization in the whole process of EPC project management.

\section{References}

1. Li Songdong. EPC general contracting model design management research. construction economy, 2012 (7): 68-70.

2. Wang Shuangjun. Combined with the research on schedule management mode of. housing industry EPC engineering BIM technology, 2016 (7): 46-60.

3. Liu Huan, Liu Shangyang. BIM technology applied to the total contract cost management advantage points Analysis of. building economy, 2013 (6): 31-34.

4. Tang Xiaoling, Tian dawn. Building information model (BIM) technology diffusion and Application Research Study. building economy, 2013 (6): 98-100.

5. Liu Wenping. BIM EPC in Guo REDCOLLAR in highway engineering application mode of. construction economy, 2014 (9): 31-34. 